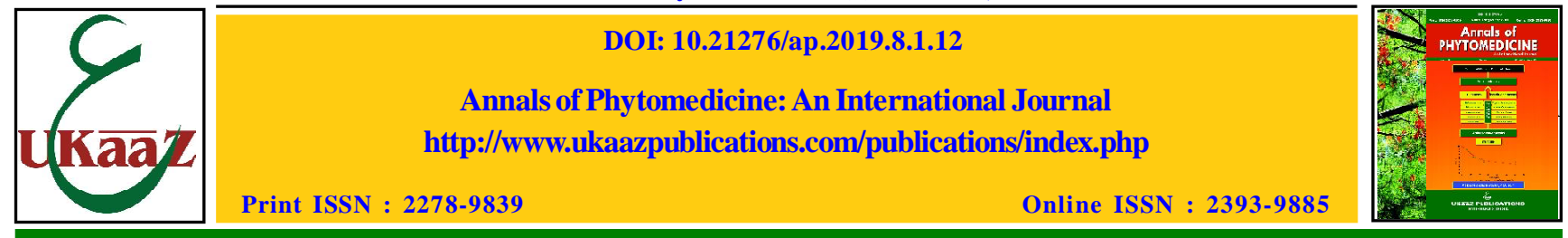

Original article

\title{
The protective effect of pomegranate juice on the ultrastructure of the testes in adult rat treated with Bisphenol-A
}

\author{
Mohamed Atif A. Said Ahmed \\ Department of Basic Medical Sciences, College of Medicine, Shaqra, Shaqra University, Kingdom of Saudi Arabia
}

Received April 23, 2019: Revised June 13, 2019: Accepted June 17, 2019: Published online June 30, 2019

\begin{abstract}
Bisphenol-A (BPA) has been considered as a risk factor for infertility because it induces testicular toxicity and acting as an endocrine disruptor. Pomegranate juice (PJ) has a variety of biological activities including potent antioxidant. The present study was designed to use a histological approach for evaluating the protective effect of PJ against BPA toxicity in the structure of the rat testes. Animals were divided into four groups. The first group was control. The second group was given $1 \mathrm{ml} \mathrm{PJ}$, while group III received $200 \mu \mathrm{g} / \mathrm{kg} / \mathrm{bw} /$ day of BPA by oral route. The fourth group received $200 \mu \mathrm{g} / \mathrm{kg} / \mathrm{bw} /$ day of BPA and $1 \mathrm{ml} \mathrm{PJ}$. Treatment was given daily for 52 days. The levels of MDA and GSH in testes were measured. Testes specimens from all groups were examined by light, scanning and transmission electron microscopes for pathological lesions. The body and testes weights, the diameter of the seminiferous tubules and the epithelial height in BPA treated rats were significantly reduced with depletion of all germinal cells while the interstitial connective tissues and spaces were wide as compared to that of control group. Treatment with PJ ameliorated the histological damage due to BPA which significantly produced oxidative stress as shown by increased MDA level and decreased GSH content. The level of oxidative stress parameters was improved in animals treated with PJ along with BPA. Electron microscopic examination revealed vacuolations and degeneration in the spermatogenic and sertoli cells in BPA treated group. Basement membrane was also found irregular. The pathological observations were with lesser degree in rats treated with BPA and PJ. The PJ may have antioxidant property and the ability to diminish the side effects of BPA on the structure of testes. Thus, PJ can be a new light in the field of infertility by reducing oxidative stress-induced damage in testes.
\end{abstract}

Keywords: Antioxidant, pomegranate juice, testes, bisphenol-A, oxidative stress

\section{Introduction}

Infertility is a global public health problem that affecting people psychosocially and medically. One of the most debated factors causing male infertility is the exposure to environmental contaminants. Recently, the chemical compound Bisphenol-A(BPA) (2, 2-bis (4 - hydroxyphenyl) propane) has been considered as a risk factor for infertility because it induces testicular toxicity and acting as an endocrine disruptor (Cariati et al., 2019; Raisuddin and Sharma, 2018).

BPA is used in the production of polycarbonated plastics, water bottles, toys, inner lining of food and beverage cans, skin emollients, perfumes, insect repellents, nail polish, hairspray, medical equipments, dental gadgets and sealants (Rubin, 2011; Huang et al., 2012; Garcia-Corcoles et al., 2018).

In human and animals, the main exposure pathway of BPA is the intake or ingestion of adulterated food and water (Geens et al., 2015). BPA can migrate into the environment, depending upon the exposure to temperature and $\mathrm{pH}$ and it has been detected in the saliva, urine, blood, and food (Calafat et al., 2009; Braun et al.,

Author for correspondence: Dr. Mohamed Atif A. Said Ahmed Department of Basic Medical Sciences, College of Medicine, Shaqra, Shaqra University, Kingdom of Saudi Arabia

E-mail: mohammedatif@su.edu.sa

Tel.: +00966508093534

Copyright () 2019 Ukaaz Publications. All rights reserved.

Email: ukaaz@yahoo.com; Website: www.ukaazpublications.com
2011; Scippo, 2011). Exposure to BPA even at low level elicits cellular and molecular alterations (Rubin, 2011; Corrales et al., 2015). BPA increases apoptosis in spermatogenic cells and disrupt the normal spermatogenesis (Li et al., 2014; Wang et al., 2017). It induces oxidative stress and can lead to male reproductive dysfunction such as decreased semen quality, decreased the level of testosterone, impair the motility of human sperm and marked sperm damage (Meeker et al., 2010).

Testicular tissue is of great importance for reproduction. Its exposure to oxidative stress has been considered as an important factor that influences male fertility status (Aitken and Roman., 2008; Wright et al., 2014). The overproduction of ROS can be detrimental to sperm function, associated with peroxidative damage to the mitochondria and plasma membrane. Spermatozoa are susceptible to peroxidative damage, because of its high contents of polyunsaturated fatty acids and its low antioxidant capacity (Van Tran et al., 2017). Furthermore, lipid peroxidation destroys the membranes of spermatozoa with loss of motility (Sanocka and Kurpisz, 2004). Many studies have been conducted on BPA regarding male reproductive toxicity, and most of these studies have consistently described its harmful effects on the testicular tissue (Doshi et al., 2013; Tiwari and Vanage, 2013; Maamar et al., 2015).

Punica granatum L., commonly known as pomegranate, belongs to family Punicaceae (Voravuthikunchai et al., 2005). Pomegranate 
contains a number of polyphenol, including anthocyanins, ellagitannins, minor flavonoids, and punicalagin. Pomegranate juice possess various pharmacological properties including potent antioxidant, anti-inflammatory, anticancer, antiangiogenesis activities, antiproliferative and antiartherogenic apoptotic (Viladomiu et al., 2013). These properties strongly suggest a wide range of using pomegranate juice (PJ) for clinical applications (Rahimi et al., 2012).

A review of literature could not reveal any results on the histological effects of the use of pomegranate juice (PJ) on testes treated with BPA.

We aim to use a histological approach to demonstrate the impact of BPA on testes injury and possible protective effect of PJ against BPA-induced alteration in the structure of the testes of the adult albino rats using light, scanning and transmission electron microscopes.

\section{Materials and Methods}

\subsection{Chemicals}

Absolute ethanol was purchased from (Merk), Bisphenol A (97\% purity) and all other chemical reagents were purchased from Sigma Aldrich (St Louis, MO, USA).

\subsection{Pomegranate juice preparation}

The fresh pomegranate fruits, free of blemishes or obvious defects were purchased from local market. Pomegranates were washed and manually peeled, without separating the seeds. Juice was obtained using a commercial blender (Hyundai, China), filtered with a Buchner funnel and immediately diluted with distilled water to volume of $1: 3$ and stored at $-20^{\circ} \mathrm{C}$ for eight weeks (Abdel Moneim et al., 2011).

The pomegranate fruits were identified and authenticated by the institutional botanist and sample specimen number SUMA1801 was kept for the future reference.

\subsection{Ethical statement}

All animal-based examinations were designed and performed with the recommendations in the Guide for the Care and Use of Laboratory Animals of National Institutes of Health. This study received ethical approval from Institutional Review Scientific Boards of Shaqra University, Shaqra, K.S.A. No\# D170425/G01/N009.

\subsection{Animals and treatments}

Forty adult male albino rats aged 7 weeks were fed ad libitum and maintained in a holding facility with constant temperature $(24 / \pm /$ $2 /{ }^{\circ} \mathrm{C}$ ) and humidity (55-60\%), as well as a regular $12 / \mathrm{h}$ light/dark circle.

\subsection{Experimental design}

Rats were randomized and divided into four groups (10 rats in each group) as follows:

Group I (control group).

Group II (pomegranate (PJ) group): The animals received PJ (1 ml/ $\mathrm{kg}$ bw/ day) orally by gavage daily for 52 days.

Group III (BPA group): The animals received $(200 \mu \mathrm{g} / \mathrm{kg} / \mathrm{bw} /$ day $)$ of BPA dissolved in corn oil orally by gavage daily for 52 days.
Group IV (PJ + BPA group): The animals received PJ $(1 \mathrm{ml} / \mathrm{kg} / \mathrm{bw} /$ day) and BPA dissolved in corn oil $(200 \mu \mathrm{g} / \mathrm{kg} / \mathrm{bw} /$ day $)$ orally by gavage daily for 52 days.

At the end of the experiment, the rats were weighed, anaesthetized with sodium thiopental $(30 \mathrm{mg} / \mathrm{kg}$, i.p.) and sacrificed. Then, the right testes from each animal was removed and weighed and rapidly dissected to be subjected to the histological examination.

\subsection{Biochemical studies for determination of oxidative stress}

The generation of reactive oxygen species in response to BPA toxicity was determined in testes by the measurement of the lipid peroxidation product content. Malondialdehyde (MDA) (OxiSelect ${ }^{\mathrm{TM}}$ TBARS Assay Kit, Cell Biolabs Inc. San Diego, USA), glutathione (GSH) (OxiSelect ${ }^{\mathrm{TM}}$ ), were measured by commercially available kits.

\subsection{Histological examination}

Testes were removed and fixed in $4 \%$ paraformaldehyde at $4{ }^{\circ} \mathrm{C}$ overnight, then dehydrated in graded ethanol, before embedding in paraffin and sectioned to $5 \mu \mathrm{m}$ thick, following standard histological procedures. After deparaffinization and rehydration (at $60^{\circ} \mathrm{C}$ for 2 $\mathrm{h}$ ), sections were processed for $\mathrm{H}$ and $\mathrm{E}$ staining as described previously (Bancroft and Stevens., 1996). Slides were mounted using entellan and covered with coverslips, then examined by (Nikon Eclipse E-200) light microscope.

\subsection{Scanning electron microscopy}

Testicular tissue was fixed with $3 \%$ glutaraldehyde in phosphate buffer for $4 \mathrm{~h}$. After the samples were washed and dehydrated, they were dried. Testes samples were mounted on an aluminium stub, then coated with gold. The specimens were examined by the scanning electron microscope. The photographs of testes tissue were recorded using SEM 6390 LV JEOL. Somniferous tubules were evaluated for tubular diameter and height of the tubular epithelium. The scale bar was $50 \mu \mathrm{m}$ and the values for the 10 somniferous tubules for each animal were measured. These averages were used for calculating means and standard deviation of means and performing statistical analysis by using Prism programmed on the computer

\subsection{Transmission electron microscopy (TEM)}

The testes specimens were cut into small pieces of $1 \mathrm{~mm}^{2}$ size, then fixed with $2.5 \%$ glutaraldehyde phosphate and $1 \%$ osmium tetroxide for $24 \mathrm{~h}$. Specimens were washed in $0.1 \mathrm{M}$ phosphate buffer at $4^{\circ} \mathrm{C}$, then post fixed in $1 \%$ osmium tetraoxide at room temperature. Afterwards, the samples were dehydrated, then embedded in epoxy resin. Semi-thin sections $(1 \mu \mathrm{m})$ were stained with toluidine blue in borax and examined with light microscope. Ultra-thin sections (50 $\mathrm{nm}$ ) were cut, mounted on copper grids and stained with uranyl acetate and lead citrate (Bancroft and Stevens, 1996). Specimens were examined and photographed using transmission electron microscope (Jeol 1200 EX, Japan).

\subsection{Data analysis}

Data presented as mean and its standard deviation. The degree of significance was set at $p<0.05$. The structural changes were analyzed by two-way analysis of variance. All data analyses were carried out using the SPSS Version 11.0 statistic software package. 


\section{Results}

The statistical analysis revealed a significant decrease $(p<0.05)$ in the body and testicular weights of the rats after BPA administration compared to the control and PJ groups. The body and testicular weights values were significantly $(p<0.05)$ higher in the BPA+ PJ group, compared to the BPA group (Table 1).

Seminiferous tubular diameter (STD) and epithelial height of seminiferous epithelium (HSE) in control and PJ groups were significantly higher $(p<0.05)$, compared to the BPA treating group. Also, STD and HSE were higher in BPA+PJ group, compared to the BPA group (Table 1).

BPA administration produced significant $(p<0.05)$ changes in the oxidative stress parameters in the rats treated with BPA as shown by increased MDA and decreased GSH content (Table 2). The level of oxidative stress parameters was improved when we administrated PJ with BPA.

Table 1: The body weight in gm, testes weight in $\mathrm{gm}$, the seminiferous tubules (ST) diameter in $\mu \mathrm{m}$ and the epithelial height in $\mu \mathrm{m}$ of the different groups

\begin{tabular}{|l|c|c|c|c|}
\hline Group & $\begin{array}{c}\text { Mean weight of } \\
\text { testes }(\mathbf{g}) \pm \text { SD }\end{array}$ & $\begin{array}{c}\text { Mean Body } \\
\text { weight }(\mathbf{g}) \pm \text { SD }\end{array}$ & $\begin{array}{c}\text { Mean ST diameter } \\
(\boldsymbol{\mu} \mathbf{m}) \pm \text { SD }\end{array}$ & $\begin{array}{c}\text { Mean epithelial } \\
\text { height }(\boldsymbol{\mu m}) \pm \text { SD }\end{array}$ \\
\hline Group I & $1.9 \pm 0.14^{\mathrm{a}}$ & $298 \pm 5.5^{\mathrm{a}}$ & $234 \pm 1.5^{\mathrm{a}}$ & $74.5 \pm 1.2^{\mathrm{a}}$ \\
Group II & $1.9 \pm 0.15^{\mathrm{a}}$ & $302 \pm 5.6^{\mathrm{a}}$ & $236 \pm 1.6^{\mathrm{a}}$ & $75.1 \pm 1.4^{\mathrm{a}}$ \\
Group III & $1.4 \pm 0.15^{\mathrm{b}}$ & $231.1 \pm 6.1^{\mathrm{b}}$ & $161 \pm 4.1^{\mathrm{b}}$ & $41.2 \pm 2.1^{\mathrm{b}}$ \\
Group IV & $1.78 \pm 0.14^{\mathrm{a}}$ & $277 \pm 5.7^{\mathrm{a}}$ & $207 \pm 3.6^{\mathrm{a}}$ & $64.4 \pm 1.9^{\mathrm{a}}$ \\
\hline
\end{tabular}

Values with different superscript in each column differ significantly $(p<0.05)$.

Table 2: Malondialdehyde (MDA) and thiol protein (GSH) levels (Mean $\pm \mathrm{SD}$ ) in rats

\begin{tabular}{|l|c|c|}
\hline Group & MDA $(\mathbf{n m o l} / \mathbf{m l})$ & GSH $(\boldsymbol{\mu m o l} / \mathbf{m l})$ \\
\hline Group I & $413.2 \pm 6.4^{\mathrm{a}}$ & $35.9 \pm 2.1^{\mathrm{a}}$ \\
Group II & $411 \pm 6.5^{\mathrm{a}}$ & $35.4 \pm 2^{\mathrm{a}}$ \\
Group III & $749.4 \pm 9.4^{\mathrm{b}}$ & $21.3 \pm 4.3^{\mathrm{b}}$ \\
Group IV & $521.6 \pm 10.7^{\mathrm{a}}$ & $29.6 \pm 3.8^{\mathrm{a}}$ \\
\hline
\end{tabular}

Values with different superscript in each column differ significantly $(p<0.05)$.

Examination of $\mathrm{H}$ and $\mathrm{E}$ stained sections of control testes showed seminiferous tubules lined with compacted and organized germinal epithelium. A series of five or more cell layers were seen in the epithelium of seminiferous tubules. Spermatogenic cells in different developmental stages were found. All types of spermatogenic cells included spermatogonia, primary spermatocytes, secondary spermatocytes, followed by early spermatids, late spermatids and finally spermatozoa which were seen in the lumen of the tubules. Both sertoli cells and spermatogonia were seen resting on the basement membrane. Interstitial tissue in-between seminiferous tubules containing clusters of leydig cells with their vesicular nuclei were observed in the interlobular spaces (Figure 1A). Similar to the control, normal histological features of rat testes were observed in the PJ group (group II) (Figure 1B).

In contrast to the control group, the histological study of testicular tissue in treated group with BPA, demonstrated that the shape of seminiferous tubules appeared irregular, the germinal epithelium layers was reduced with mal-arranged and the cells of germinal epithelium had abnormal cellular attachment. Spermatogonia were separated from the intact membrane. The spermatogonia cells were the major cell type that seen. Few spermatids were seen in many tubules, but mature spermatozoa were rarely found. Multinucleated giant cells were revealed. Degeneration and necrosis in spermatogenic cells were also observed. Vacuolization among germ cells were observed in the seminiferous tubules. The centre of tubules was empty or filled with debris of broken and fragmented spermatozoa. The interstitial tissues and spaces were wide compared with the control group. Leydig cells were very low in number in the interlobular spaces of tubules (Figure 1C).

Treatment with PJ ameliorated the histological damage due to BPA. The outlay of tubules was round, as in the control group. Spermatogonia were present along with the germinal epithelium. Spermatogenic cells greatly increased in number. Spermatids were also seen in many tubules, but mature spermatozoa were less than normal. The lumens of tubules were in the process of restoration. The number of leydig cells was also increased compared to the BPA group (Figure 1D).

The present results of scanning electron microscopy study of control group revealed that, the outer surface of the seminiferous tubule is enveloped with single layer of flat myoid cells, whose nuclei appear as small bulges. Germ cells layers and spermatozoa are clearly seen. The lumens of seminiferous tubules were filled with mature sperm or spermatozoa, and the heads of sperms were observed clearly. The interstitial tissue forms a delicate lattice with marked spaces in-between the seminiferous tubules (Figure 2A). The same results was revealed in PJ group (Figure 2B).

BPA treated group showed irregularity of the outer surface of seminiferous tubules, internal cavities with different sizes, depletion of the germinal epithelial layers and low epithelial height (Figure 2C). BPA treated group with PJ revealed marked improvement of the shape of outer surface (Figure 2D).

Transmission electron microscopic examination of the control and PJ groups showed normal seminiferous tubular structure with normal morphology of sertoli cells with their idented nuclei resting on regular basement membrane surrounded by myoid cells with flat nuclei. Spermatogonia cell is seen closed to the sertoli cell. Primary spermatocytes with their large nuclei appeared in the second layer (Figure 3 A, B). Normal morphology of spermatids and spermatozoa were seen (Figure 4 A, B). 
BPA group showed sertoli cells with many basal mitochondria, some of them were ring shaped. Large vacuoles were also seen in the sertoli cells. The basement membrane was thin and irregular. The outer membrane of myoid cells revealed irregularity in thickness with destructed areas. Large vacuoles showed in the spermatogenic cells. Vacuolization of spermatogonia were cleared in most of seminiferous tubules. Some early spermatids were seen in the second
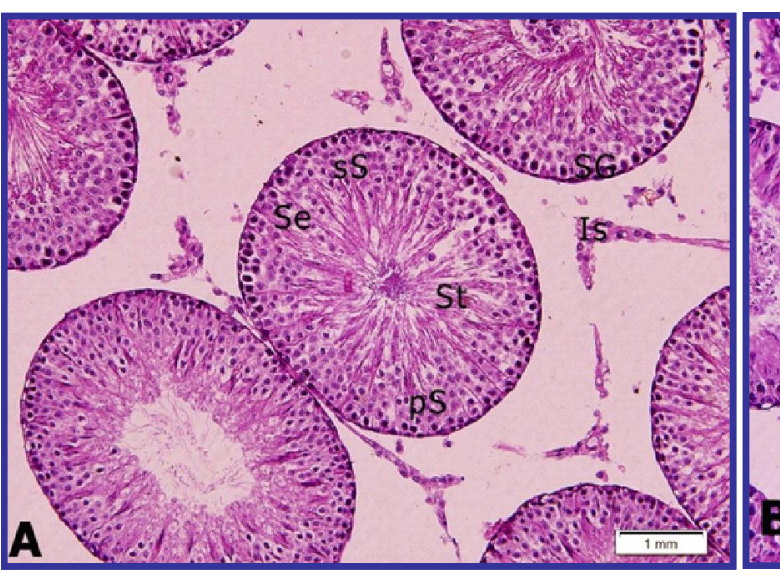

layer with condensed of the outer nuclear chromatin and some nuclei were atrophic (Figure 3C). Fragmented nuclear membranes of spermatids were noted at many points. The head of spermatozoa has deformed nuclei and many vacuoles (Figure 4C). Coadministration of PJ with BPA revealed marked improvement of all pathological changes that was seen by electron microscopes (Figure $3 \mathrm{D}$ and $4 \mathrm{D})$.
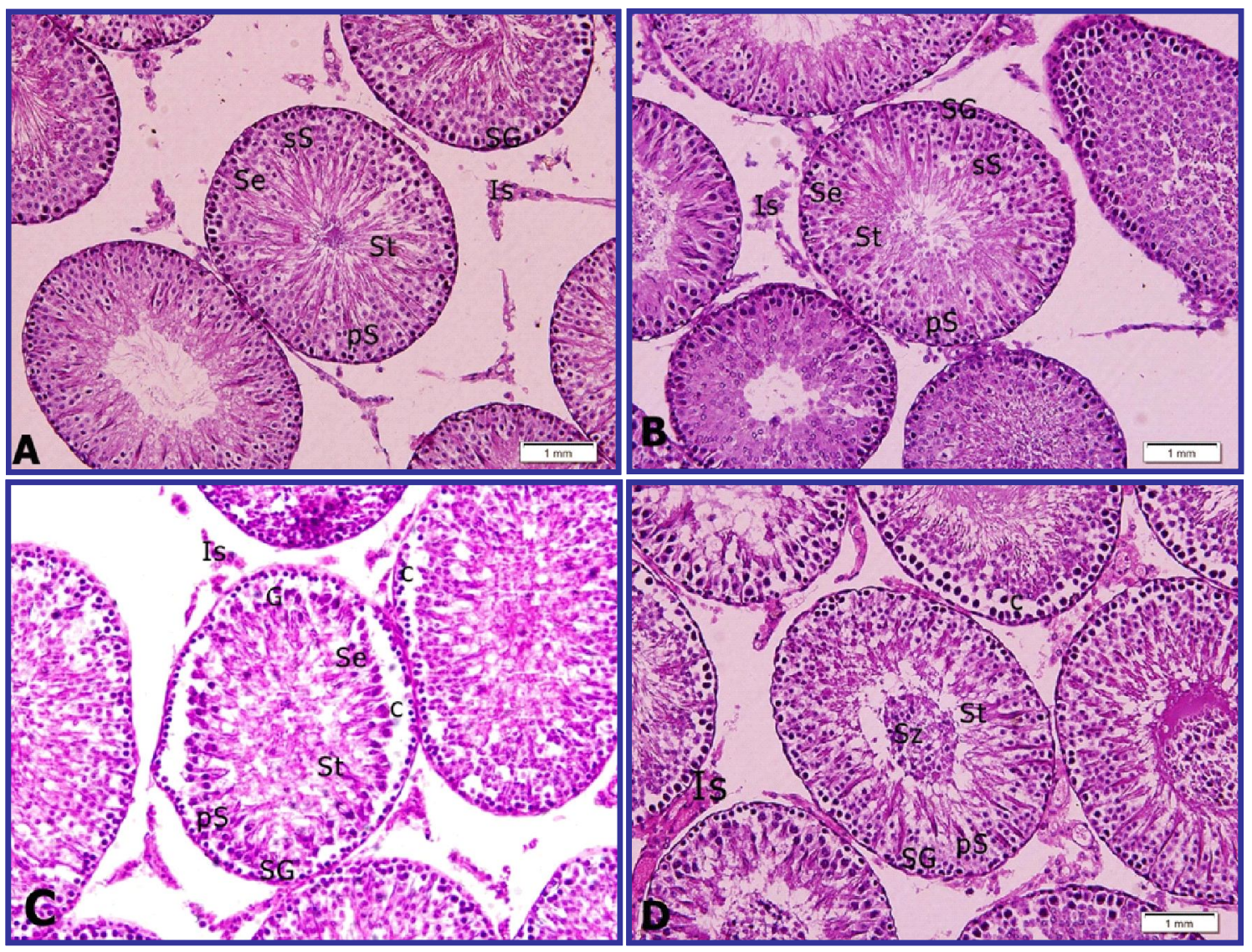

Figure 1: (A) A photomicrograph of testicular tissue of a rat from the control group showing leydig cells in the interstitial tissues (Is), spermatogonia (SG), sertoli cells $(\mathrm{Se})$, primary spermatocytes $(\mathrm{pS})$, secondary spermatocyte $(\mathrm{sS})$ and elongated spermatids $(\mathrm{St})$. (H and E X 200). (B) A photomicrograph of testicular tissue of a rat from group II showing leydig cells in the interstitial tissues (Is), spermatogonia (SG), sertoli cells $(\mathrm{Se})$, primary spermatocytes $(\mathrm{pS})$, secondary spermatocyte $(\mathrm{sS})$ and elongated spermatids $(\mathrm{St})$. (H and E X 200). (C) A photomicrograph of testicular tissue of group III treated with BPA showing depletion of germ cells. The germinal epithelium is disorganized with many vacuoles and cavities (c), spaces and degenerated areas. Multinucleated giant cells $(\mathrm{G})$, spermatogonia (SG), primary spermatocytes (pS), sertoli cells (Se) and spermatids (St) are present. The outer layer of the seminiferous tubule is disrupted at certain areas. The interstitial tissue and spaces are wide. (H and E X 200). (D) A photomicrograph of testicular tissue of a rat from group IV showing leydig cells in the interstitial tissues (Is), spermatogonia (SG), sertoli cells (Se), primary spermatocytes $(\mathrm{pS})$, spermatids $(\mathrm{St})$ and spermatozoa $(\mathrm{Sz})$. Minimal pathological changes were noted comparing to the III group. (H and E X 200).

\section{Discussion}

BPA significantly decreased the body weight of rats which is supported by previous study by Chitra et al. (2003). Some studies showed non-significant differences in body weight of rats (Aydogan et al, 2008) while other indicated significant changes in body weight (Rice-Evans et al., 1997). These discrepancies in weight changes may be related to the differences in doses, routes of administration, duration, and time of treatment (Mourad and Khadrawy, 2012). High doses of BPA reported to cause the significant decrease in the final body weights of rats (Nanjappa et al., 2012). One study report indicated that the body weight of male rats was not significantly affected with low doses of BPA (Norazit et al., 2012).

Weight loss in BPA-treated group may confirm that BPA affects the metabolic rate of the animals, following long-term exposure (Yousaf et al., 2016). BPA can cause a decrease in the testosterone level by lowering the antioxidant capacity and blocking P450 cytochrome (Akingbemi et al., 2004). Decrease in the level of testosterone could induce weight loss by decreasing muscles and bone mass (Isidori et $a l ., 2005)$. The significant decrease in the weight of the testes of the BPA-treated group compared to the control indicates the toxicity 
to the testes. Previous study conducted by Akingbemi et al. (2004), showed that the testes weight of rats decreased due to exposure to BPA. Reductions in the weight of the testes were also due to damage of primary spermatocytes and spermatids because spermatogonia need testosterone to begin their function, and BPA-treated rats had very low levels of this hormone (Mourad and Khadrawy, 2012), which indicate the cause of spermatogenesis failure.
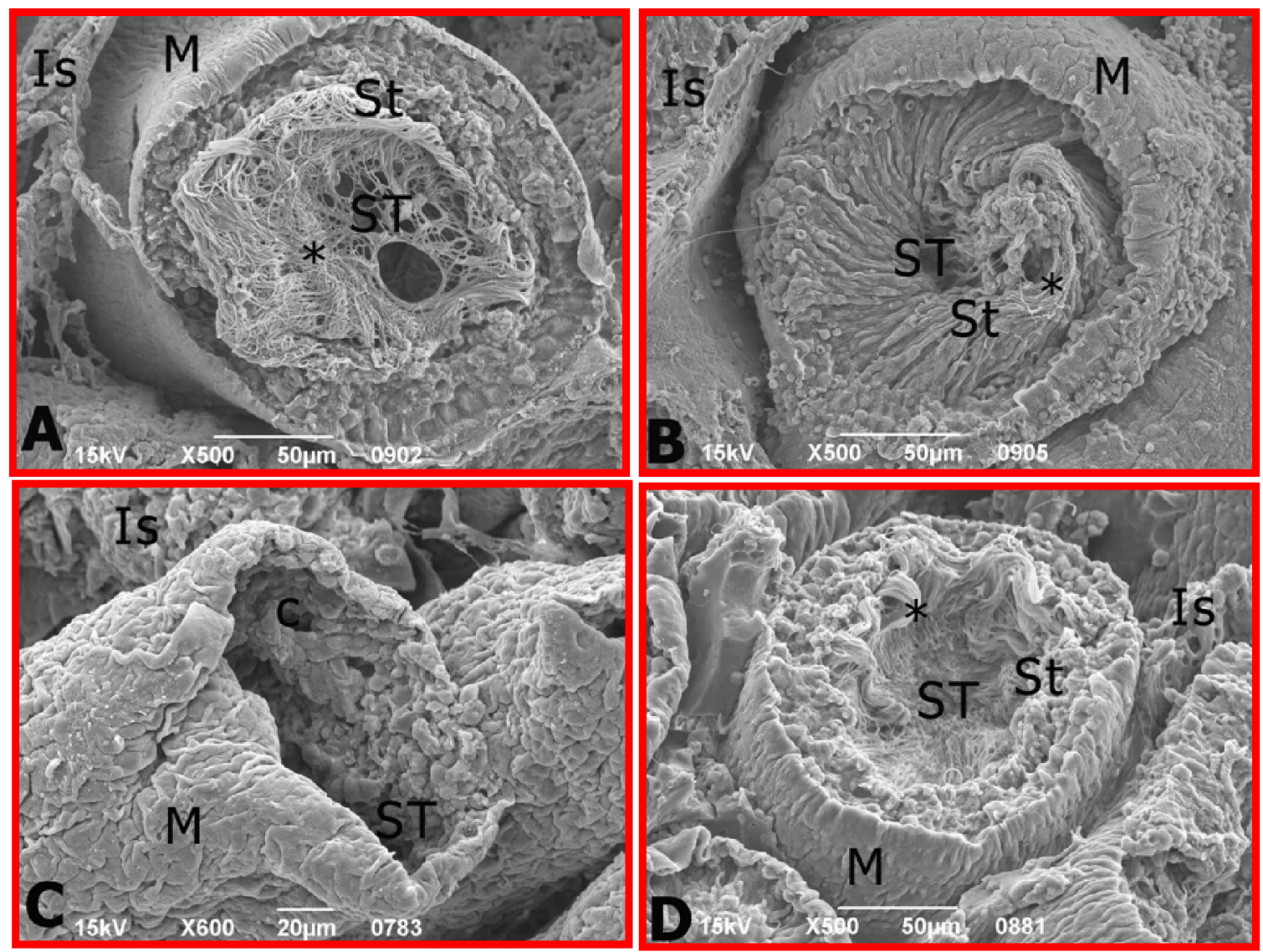

Figure 2: (A) Scanning electron micrograph of testicular sections of rats of the control group showing: seminiferous tubule (ST) with flat myoid cells (M) and interstitial tissue (Is) in between. Notice the presence of spermatids (St) and spermatozoa with long flagellae (asterisk) in its lumen. (bar $=50 \mu \mathrm{m} \mathrm{X} \mathrm{500).} \mathrm{(B)} \mathrm{Scanning} \mathrm{electron} \mathrm{micrograph} \mathrm{of} \mathrm{testicular} \mathrm{sections} \mathrm{of} \mathrm{rats} \mathrm{of} \mathrm{the} \mathrm{PJ} \mathrm{treated} \mathrm{group}$ showing: seminiferous tubule (ST) with flat myoid cells (M) and interstitial tissue (Is) in between. Notice that its lumen is completely occupied by spermatids (St) and spermatozoa with long flagellae (asterisk). (bar $=50 \mu \mathrm{m} \quad \mathrm{X} 500$ ). (C): Scanning electron micrograph of testicular sections of rats treated with BPA group showing: seminiferous tubule (ST) with flat myoid cells (M) and wide interstitial tissues (Is) and spaces. Notice the irregularity of the ST outline and the presence of cavities (c) inside the ST with the depletion of the germinal epithelial layers and low epithelial height. (bar $=20 \mu \mathrm{m} \mathrm{X} \mathrm{600).} \mathrm{(D)} \mathrm{Scanning} \mathrm{electron}$ micrograph of testicular sections of rats treated with BPA and PJ showing: seminiferous tubule (ST) with flat myoid cells (M) and wide interstitial tissues (Is) and spaces. Notice the irregularity of the ST outline, the presnce of cavities and the depletion of the germinal epithelial layers and the epithelial height are improved and many spermatids ( $\mathrm{St}$ ) and spermatozoa are present with their flagellae (asterisk) in the lumen. (bar $=50 \mu \mathrm{m} \mathrm{X500).}$

In the group treated with BPA, we observed that there was a marked change in the histology of the testes by decreasing the height of epithelial tissues and the diameter of seminiferous tubules. These results may be due to the BPA toxicity, the significant reduction in the weight of testes and the low serum testosterone level (Jin et al., 2013). BPA has inhibitory effects on the gonadal axis in males, and the elevation of estrogen inhibits spermatogenesis and testicular testosterone secretion (Richter et al., 2007).

The histological changes can be due to the increase in ROS (Devasagayam et al., 2004). When the cells lose its ability to detoxify ROS, they go into oxidative stress, which causes a reduction in the level of antioxidant enzymes (Pérez et al., 2009). A study by Macao et al. (2017) showed that the oxidative action of BPA increased the level of ROS. Data from present study likely revealed that treatment with BPA disrupts oxidant-antioxidant balance in testes so that the levels of MDA significantly increased along with significant decreased in levels of GSH. The strong antioxidant property of PJ resulted in significant increase in GSH. The PJ was found to be effective in increasing the GSH and decreasing the MDA compared to the BPA group. The present findings confirmed the results of a previous study conducted by Moghaddam et al. (2015). The previously recorded antioxidant effect of PJ was due to its polyphenolic contents (Viladomiu et al., 2013). Also, Zhao et al. 
(2016) showed that the PJ can reduce highly reactive oxygen species that can cause extensive damage to cell membranes lipids, and decrease MDA, which is in consistency with our study. The PJ has antioxidant properties that may decrease the toxic effects of BPA. PJ contains polyphenols, tanins, anthocyanins and punicalgin bioactive constituent responsiple mainly for antioxidant activity of PJ.
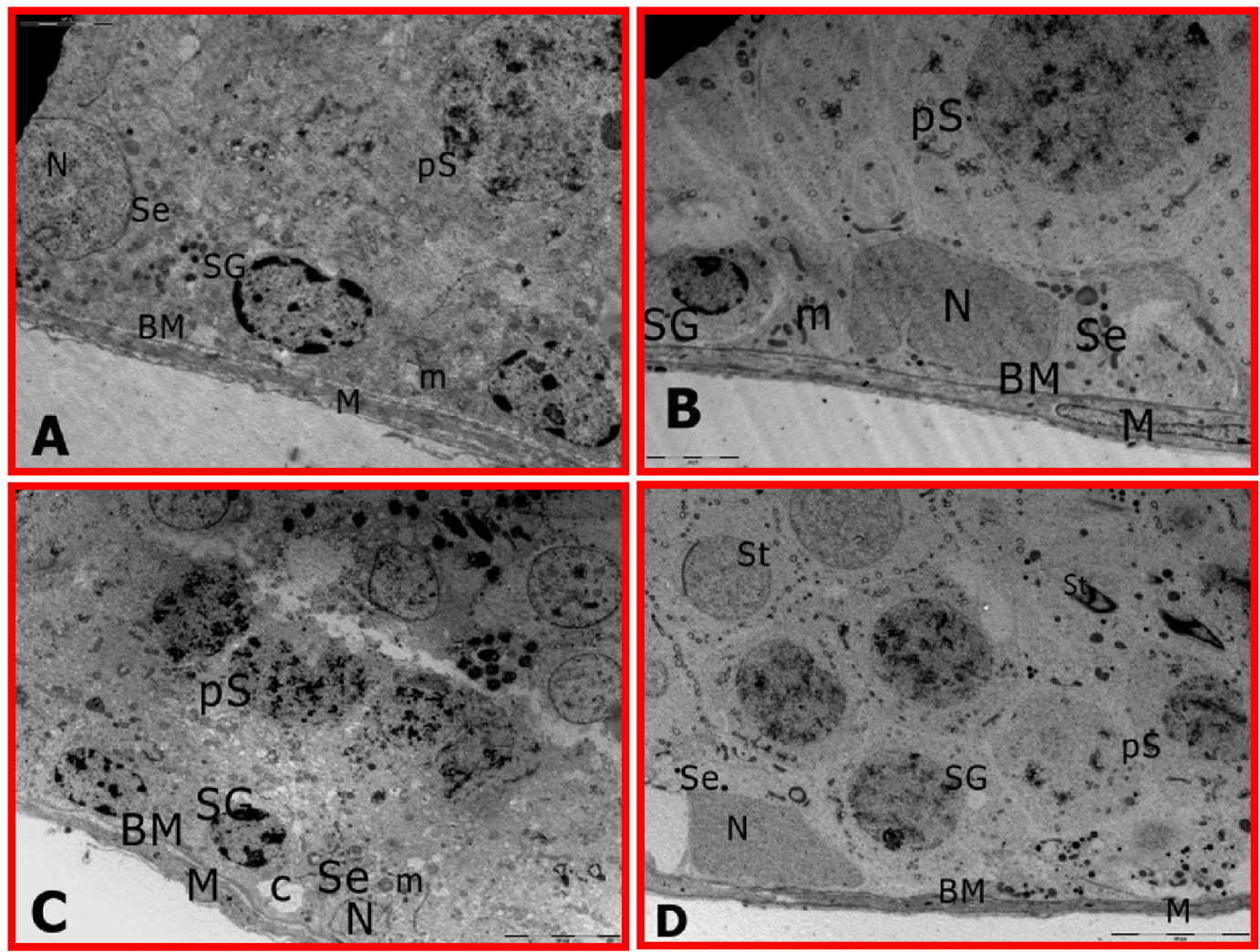

Figure 3: (A) Transmission electron micrograph of testicular sections of rats of the control group showing: sertoli cell (Se) with its idented nucleus (N), spermatogonia (SG) with basal mitochondria (m) closed to regular basement membrane (BM) and flat myoid cell (M). Notice the presence of primary spermatocyte cell $(\mathrm{pS})$ with its large nucleus $(\mathrm{N})$. ( bar $=5 \mu \mathrm{m} \mathrm{X} \mathrm{4000).} \mathrm{(B)} \mathrm{Transmission} \mathrm{electron}$ micrograph of testicular sections of rats of the PJ treated group showing: spermatogonia (SG), and sertoli cell (Se) with its idented nucleus $(\mathrm{N})$ resting on the regular basement membrane $(\mathrm{BM})$ with flat myoid cell $(\mathrm{M})$. Notice the presence of primary spermatocyte cell $(\mathrm{pS})$ with its large nucleus $(\mathrm{N})$. ( $\mathrm{bar}=5 \mu \mathrm{mX} 4000)$. (C) Transmission electron micrograph of testicular sections of rats of BPA treated group showing: irregular basement membrane (BM), atrophy of sertoli cell $(\mathrm{Se})$ nucleus $(\mathrm{N})$ with the presence of vacuoles (c) and many mitochondria, some of them are ring shaped, flat myoid cells (M) with irregular thickness. Notice the presence of spermatogonia (SG) and primary spermatocytes (pS). ( bar $=10 \mu \mathrm{m} \mathrm{X} \mathrm{2500).} \mathrm{(D)} \mathrm{Transmission} \mathrm{electron} \mathrm{micrograph} \mathrm{of} \mathrm{testicular}$ sections of rats treated with BPA and PJ showing: sertoli cell (Se) with nucleus $(\mathrm{N})$ resting on regular basement membrane (BM) with the presence of flat myoid cells $(\mathrm{M})$ spermatogonia $(\mathrm{SG})$ and primary spermatocyte $(\mathrm{pS})$. Notice the presence of some spermatids (St) in the second layer. ( $b a r=10 \mu \mathrm{m} \mathrm{X} \mathrm{3000).}$

Bisphenol-A disrupts testicular germ cell population and induces oxidative stress causing the production of inflammatory cytokines and ROS generation (Wang et al., 2017; Meeker et al., 2010). Histopathological changes in testicular tissue have been widely used as significant biological indicators to investigate the toxicity of environmental pollutants (Hinton et al., 1992; Bhuiyan et al., 2001).

Histology of the testes in the PJ group in this work exhibited the same features as in the control group, indicating that there are no side effects of PJ on rat testes. Oxidative stress has been implicated as a key event in BPA toxicity. The histological studies revealed marked damages in testes like deformity in the seminiferous tubules, vacuolization in tubules and empty lumen, rupture of the germinal membrane surrounding the tubule and degeneration of spermatogenic cells with shrinkage of nuclei in the primary spermatocytes and sloughing of spermatogenic cells from the basement membrane. BPA testicular toxicity is associated with apoptosis induction. Reduction in spermatogenic cell types as spermatocyte and spermatids. Interlobular spaces were increased in between the tubules. Similar pathological changes at high and low doses of BPA were observed in the testes of rats by Hassan et al. (2013) and Gurmeet et al. (2014). Exposure of BPA even with low doses caused anomalies in sperm morphology results in infertility (Chitra et al., 2003). A reduction in the number of leydig cells could be responsible for these defects. Leydig cells produce testosterone, which is required by the spermatogonia for further processing of spermatogenesis. Membranes of sperm has a higher concentration of fatty acids and are highly sensitive to oxidative damage. Damage to this membrane decreases the movement of sperm. Abnormal sperm morphology leads to slow movement which is responsible for infertility (El Ghazzawy et al., 2011). 

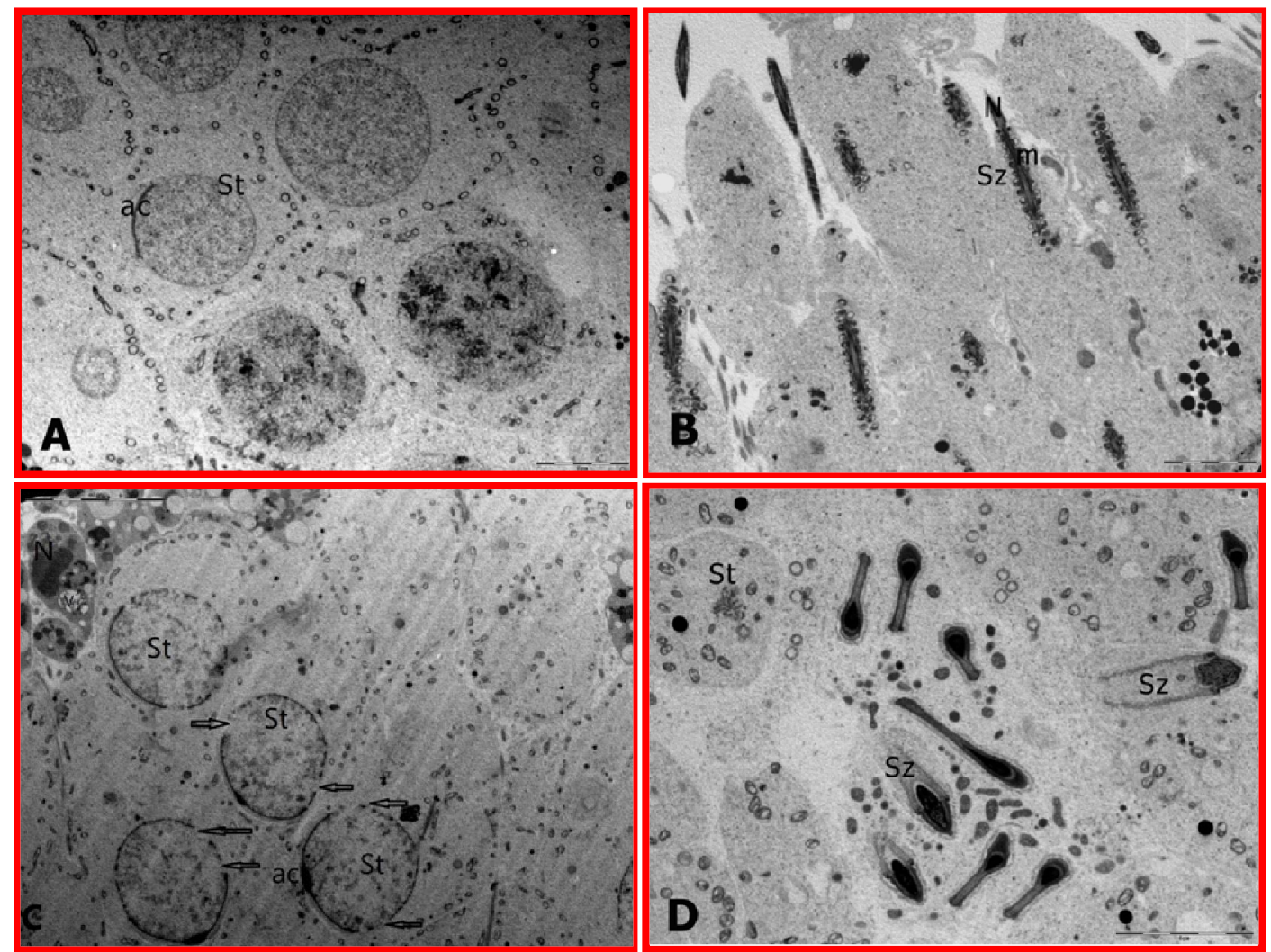

Figure 4: (A) Transmission electron micrograph of testicular sections of rats of the control group showing: many spermatids (St) with their acrosomal cap (ac). ( bar $=5 \mu \mathrm{m} \mathrm{X} \mathrm{4000).} \mathrm{(B)} \mathrm{Transmission} \mathrm{electron} \mathrm{micrograph} \mathrm{of} \mathrm{testicular} \mathrm{sections} \mathrm{of} \mathrm{rats} \mathrm{of} \mathrm{the} \mathrm{PJ} \mathrm{group}$ showing: large numbers of spermatozoa (Sz) close the lumen. Notice the mitochondria $(\mathrm{m})$ and the nucleus $(\mathrm{N})$. ( $\operatorname{bar}=5 \mu \mathrm{m} \mathrm{X}$ 4000). (C) Transmission electron micrograph of testicular sections of rats of the BPA group showing: spermatids (St) in cap phase with their acrosomal cap (ac) close to the lumen. Notice the fragmented nuclear membranes at many points (arrow). The head of spermatozoa has deformed nuclei (N) and many vacuoles (v). ( bar $=10 \mu \mathrm{m} \mathrm{X} \mathrm{3000)} \mathrm{(D)} \mathrm{Transmission} \mathrm{electron} \mathrm{micrograph} \mathrm{of}$ testicular sections of rats of BPA treated and PJ showing: spermatids (St) and many spermatozoa (Sz). ( $\mathrm{bar}=5 \mu \mathrm{m} \mathrm{X} \mathrm{6000).}$

All pathological changes induced by BPA, were ameliorated when PJ was co-administered with BPA. This is because flavonoids present in PJ can increase the level of testosterone. Also, antioxidant compounds found in PJ prohibit reductions in the number of leydig and sertoli cells. Antioxidant improves testes weight, seminiferous tubule diameter and thickness of the germinal epithelium (Estakhr and Javdan, 2011). Antioxidants proved to be favorable in working against oxidative stress. Pomegranate plays a significant antioxidant role in vitro and in different diseases (Seeram et al., 2005; Lorena et al., 2014). Recent studies demonstrated that treatment of rat with pomegranate juice can prevent oxidative stress induced testicular damage leading to infertility (Sherif et al., 2013; AlOlayan et al., 2014).

The present results demonstrate that the PJ have antioxidant properties which leads to protective effect against deteriorations caused by BPA.

Our results revealed that BPA-induced oxidative stress mediated damage, can be decreased by use of phytoremedy like pomegranate juice. Pomegranate juice can be a new light in the field of infertility by reducing oxidative stress damage in testes. Nonetheless, additional studies are recommended on this subject before the clinical application can be endorsed.

\section{Conclusion}

In light of the present results, BPA induces severe testicular pathological changes in adult male albino rats. BPA administration caused a significant decrease in the body and testes weight. These changes are arbitrated by oxidative stress due to the administration of BPA. Co-administration of PJ with BPA prevented testes from experiencing the deleterious effects of BPA. Damages caused under the effect of BPA were noticeably reduced after treatment with PJ. Histological disruptions due to BPA were also recovered withtreatment of PJ. Further, multidimensional research is needed to elucidate the mechanism of PJ in protecting spermatogenesis.

\section{Acknowledgments}

This study was financially supported (grant\#Shaqra-Med-38/39) by the Deanship of Scientific Research, Shaqra University, Shaqra, Kingdom of Saudi Arabia.

\section{Conflict of interest}

The author declare that no conflict of interest exists in the course of conducting this research. The author had final decision regarding the manuscript and the decision to submit the findings for publication. 


\section{References}

Abdel Moneim, A.E.; Dkhil, M.A. and Saleh Al-Quraishy, S. (2012). Studies on the effect of pomegranate (Punica granatum L.) juice and methanolic peel extract on testis of male rats. J. Medi. Plant Res., 55:5083-5088.

Aitken, R.J. and Roman, S.D. (2008). Antioxidant systems and oxidative stress in the testes. Oxid. Med. Cell Longev., 1:15-24.

Akingbemi, B.T.; Sottas, C.M.; Koulova, A.I.; Klinefelter, G.R. and Hardy, M.P. (2004). Inhibition of testicular steroidogenesis by the xenoestrogen bisphenol-A is associated with reduced pituitary luteinizing hormone secretion and decreased steroidogenic enzyme gene expression in rat leydig cells. Endocrinology, 145(2):592-603.

Al-Olayan, E.M.; El-Khadragy, M.F.; Metwally, D.M. and Abdel Moneim, A.E. (2014). Protective effects of pomegranate (Punica granatum) juice on testes against carbon tetrachloride intoxication in rats. BMC Complement. Altern. Med., 14:164.

Aydogan, M.; Korkmaz, A.; Barlas, N. and Kolankaya, D. (2008). The effect of vitamin $\mathrm{C}$ on bisphenol-A, nonylphenol and octylphenol induced brain damages of male rats. Toxicology, 249(1):35-39.

Bancroft, J.D. and Stevens, A. (1996). Theory and practice of histological techniques. 4th edition. Churchill Livingstone: London, Toronto.

Bhuiyan, A.S.; Badrun, N. and Quamrun, N. (2001). Effects of sumithion on the histological changes of spotted Murrel, Channa punctatus (bloch). Pak. J. Biol. Sci., 4:1288-1290.

Braun, J.M.; Kalkbrenner, A.E.; Calafat,A.M.; Yolton, K.; Ye, X.; Dietrich, K.N and Lanphear, B.P. (2011). Impact of early-life bisphenol-A exposure on behavior and executive function in children. Pediatrics, 128: 873-882.

Calafat, A.M.; Weuve, J.; Ye, X.; Jia, L.T.; Hu, H.; Ringer, S.; Huttner, K. and Hauser, R. (2009). Exposure to bisphenol - A and other phenols in neonatal intensive care unit premature infants. Environ. Health Perspect., 117(4):639-644.

Cariati, F.; D'Uonno, N.; Borrillo, F.; Iervolino, S.; Galdiero, G. and Tomaiuolo, R. (2019). Bisphenol-A : An emerging threat to male fertility. Reprod. Biol. Endocrinol., 17(1):6.

Chitra, K.; Rao, K.R. and Mathur, P.P. (2003). Effect of bisphenol-A and coadministration of bisphenol-A and vitamin $\mathrm{C}$ on epididymis of adult rats: A histological and biochemical study. Asian J. Androl., 5(3):203-208.

Corrales, J.; Kristofco, L.A.; Steele, W.B.; Yates, B.S.; Breed, C.S.; Williams, E.S and Brooks, B.W. (2015). Global assessment of bisphenol - A in the environment: Review and analysis of its occurrence and bioaccumulation. Dose Response, 29:15593258-15598308.

Devasagayam, T.P.A.; Tilak, J.C.; Boloor, K.K.; Ketaki Sane, S.; Saroj, S. and Ghaskadbi Lele, R.D. (2004). Free radicals and antioxidants in human health: Current status and future. J. of Association of Physician of India, 52:794-804

Doshi, T.; D'Souza, C. and Vanage, G. (2013). Aberrant DNA methylation at Igf2-H19 imprinting control region in spermatozoa upon neonatal exposure to bisphenol-A and its association with post implantation loss. Mol. Biol. Rep., 40:4747-4757.

El Ghazzawy, I.F.; Meleis, A.E.; Farghaly, E.F. and Solaiman, A. (2011). Histological study of the possible protective effect of pomegranate juice on bisphenol-A induced changes of the caput epididymal epithelium and sperms of adult albino rats. Alexandria Journal of Medicine, 47(2):125-137.

Estakhr, J. and Javdan, N. (2011). Spermatogenic activity of Aloe vera in adult male rats. Pharmacologyonline, 2:886-889.

Garcia-Corcoles, M.T.; Cipa, M.; Rodriguez-Gomez, R.; Rivas, A.; Olea-Serrano, F.; Vílchez, J.L. and Zafra-Gomez, A (2018). Determination of bisphenols with estrogenic activity in plastic packaged baby food samples using solid-liquid extraction and clean-up with dispersive sorbents followed by gas chromatography tandem mass spectrometry analysis. Talanta, 178:441-448.
Geens, T; Dirtu, A.C.; Dirinck, E.; Malarvannan, G; Van Gaal, L.; Jorens, P.G. and Covaci, A. (2015). Daily intake of bisphenol-A and triclosan and their association with anthropometric data, thyroid hormones and weight loss in overweight and obese individuals. Environ. Int., 76:98-105.

Gurmeet, K.S.S.; Rosnah, I.; Normadiah, M.K.; Das, S. and Mustafa, A.M. (2014). Detrimental effects of bisphenol-A on development and functions of the male reproductive system in experimental rats. Excli. J., 13: $151-160$.

Hassan, A.H.; Ismail, A.A. and Khudir, A.N. (2013). Effects of pre-and postnatal exposure to bisphenol-A on the reproductive efficacy in male albino rats. J. Kerbala Univ., 11:158-172.

Hinton, D.E.; Baumann, P.C.; Gardener, W.E.; Hawkins, W.E. and Hendricks, J.D. (1992). Histopathologic biomarkers. In: Biochemical, physiological and histological markers of anthropogenic stress. Lewis Publishers, Boaco Rato, pp:155-209.

Huang, Y.Q.; Wong, C.K.; Zheng, J.S.; Bouwman, H.; Barra, R.; Wahlstrom, B.; Neretin, L. and Wong, M.H. (2012). Bisphenol-A (BPA) in China: A review of sources, environmental levels, and potential human health impacts. Environ. Int., 42:91-99.

Isidori, A.M.; Giannetta, E.; Greco, E.A.; Gianfrilli, D.; Bonifacio, V. and Isidori, A. (2005). Effects of testosterone on body composition, bone metabolism and serum lipid profile in middle-aged men: A metaanalysis. Clin. Endocrinol., 63(3):280-293.

Jin, P.; Wang, X.; Chang, F.; Bai, Y.; Li, Y. and Zhou, R. (2013). Low dose bisphenol-A impairs spermatogenesis by suppressing reproductive hormone production and promoting germ cell apoptosis in adult rats. J. Biomed. Res., 27(2):135-144

Li, J.; Chen, F.; Li, C. and Chen, Y. (2014). Quinestrol induces spermatogenic apoptosis in vivo via increasing pro-apoptotic proteins in adult male mice. Tissue Cell, 46(5):318-325.

Li, W.; Khor, T.O.; Xu, C.; Shen, G. and Jeong, W.S. (2008). Activation of Nrf2 antioxidant signaling attenuates NF kappa B-inflammatory response and elicits apoptosis. Biochem. Pharmacol., 76:14851489.

Lorena, T.; Aneta, W. and Esther, S. (2014). Antioxidant activity and proteinpolyphenol interactions in a pomegranate (Punica granatum L.) Yogurt. J. Agric. Food Chem., 62:6417-25.

Maamar, M.B.; Lesne, L.; Desdoits-Lethimonier, C.; Coiffec, I; Lassurguere, J.; Lavoue, V.; Deceuninck, Y.; Antignac, J.P.; Le Bizec, B.; Perdu, E.; Zalko, D.; Pineau, C.; Chevrier, C.; Dejucq-Rainsford, N.; Mazaud-Guittot, S. and Jegou, B. (2015). An Investigation of the endocrine-disruptive effects of bisphenol-A in human and rat fetal testes. PLoS One, 10: e0117226.

Macczak, M.; Cyrkler, B.; Bukowska, J. and Michaowicz (2017). Bisphenol-A.; bisphenol-S, bisphenol-F and bisphenol-AF induce different oxidative stress and damage in human red blood cells (in vitro study). Toxicol. In vitro, 41:143-149.

Meeker, J.D.; Ehrlich, S.; Toth, T.L.; Wright, D.L.; Calafat,A.M.; Trisini, A.T.; Ye, $X$. and Hauser, R. (2010). Semen quality and sperm DNA damage in relation to urinary Bisphenol-A among men from an infertility clinic. Reprod. Toxicol., 30(4):532-539.

Moghaddam, H.S.; Samarghandian, S. and Farkhondeh, T. (2015). Effect of bisphenol-A on blood glucose, lipid profile and oxidative stress indices in adult male mice. Toxicol. Mech. Methods, 25(7):507513.

Mourad, I.M. and Khadrawy, Y.A. (2012). The sensetivity of liver, kidney and testis of rats to oxidative stress induced by different doses of bisphenol-A. Life Science, 2(2):19-28.

Nanjappa, M.K.; Simon, L. and Akingbemi, B.T. (2012). The industrial chemical bisphenol-A (BPA) interferes with proliferative activity and development of steroidogenic capacity in rat leydig cells. Biol. Reprod., 86(5):1-12.

Norazit, A.; Mohamad, J.; Razak, S.A.; Abdulla, M.A.; Azmil, A. and Mohd. M.A. (2012). Effects of soybean extract, bisphenol-A and $17 \beta$-estradiol on the testes and circulating levels of testosterone and estradiol among peripubertal juvenile male sprague-dawley rats. Sains Malays, 41(1):63-69. 
Rahimi, H.R.; Arastoo, M. and Ostad, S.N. (2012). A comprehensive review of Punica granatum (Pomegranate) properties in toxicological, pharmacological, cellular and molecular biology researches. Iran J. Pharm. Res., 11(2):385-400.

Raisuddin, S. and Sharma, S. (2018). Endocrine-disrupting chemicals in food and their toxicological implications. Food Toxicology: Current Advances and Future Challenges, Apple Academic Press Inc. Oakville, Canada, pp:199-250.

Rice-Evans, C.; Miller, N. and Paganga, G. (1997). Antioxidant properties of phenolic compounds. Trends Plant Sci., 2(4):152-159.

Rubin, B.S. (2011). Bisphenol-A: An endocrine disruptor with widespread exposure and multiple effects. J. Steroid Biochem. Mol. Biol., 127:27-34.

Sanocka, D. and Kurpisz, M. (2004). Reactive oxygen species and sperm cells. Reprod. Biol. Endocrinol., 2:12.

Scippo, M.L. (2011). Bisphenol-A in our food: Same toxicological studies but different risk assessment and risk management decisions around the world. Food Sci. Law, pp:5.

Seeram, N.P.; Adams, L.S.; Henning, S.M.; Niu, Y. and Zhang, Y. (2005). In vitro antiproliferative, apoptotic and antioxidant activities of punicalagin, ellagic acid and a total pomegranate tannin extract are enhanced in combination with other polyphenols as found in pomegranate juice. J. Nutr. Biochem., 16:360-367.

Sherif, W.M.; Sibghatullah, S.; Sree, H.; Mueen, A.K. and Ibrahim, A.R. (2013) Sensibility of male rats fertility against olive oil, Nigella sativa oil and pomegranate extract. Asian Pac. J. Trop. Biomed., 3: 563-568.

Tiwari, D. and Vanage, G. (2013). Mutagenic effect of bisphenol-A on adult rat male germ cells and their fertility. Reprod. Toxicol., 40:60-68.
Van Tran, L.; Malla, B.A.; Kumar, S. and Tyagi, A.K. (2017). Polyunsaturated Fatty acids in male ruminant reproduction: A review. AsianAustralas J. Anim. Sci., 30(5):622-637.

VI Perez, A.; Bokov, H.; Van Remmen, J.; Mele, Q.; Ran, Y.; Ikeno, A. and Richardson (2009). Is the oxidative stress theory of ageing dead? Biochim. Biophys. Acta. Gen. Subj., 1790:1005-1014.

Viladomiu, M.; Hontecillas, R.; Lu, P. and Bassaganya-Riera, J. (2013). Preventive and prophylactic mechanisms of action of pomegranate bioactive constituents. Evid. Based Complement. Alternat. Med., pp:1-18.

Voravuthikunchai, S.P.; Sririrak, T.; Limsuwan, S.; Supawita, T. and lida, T. (2005). Inhibitory effects of active compounds from Punica granatum pericarp on verocytotoxin production by enterohemorrhagic Escherichia coli O157:H7. J. Health Sci., 51:590-596.

Wang, C.; Zhang, J.; Li, Q.; Zhang, T.; Deng, Z.; Lian, J.; Jia, D.; Li, R.; Zheng, T.; Ding, X.; Yang, F.; Ma, C.; Wang, R.; Zhang, W. and Guo Wen, J. (2017). Low concentration of BPA induces mice spermatocytes apoptosis via GPR30. Oncotarget., 8(30):49005-49015.

Wright, C.; Milne, S. and Leeson, H. (2014). Sperm DNA damage caused by oxidative stress: Modifiable clinical, lifestyle and nutritional factors in male infertility. Reprod. Biomed. Online, 28:684-703.

Yousaf, B.; Amina Liu, G.; Wang, R.; Qadir, A. and Ali, M.U. (2016). BisphenolA exposure and healing effects of Adiantum capillus-veneris L. plant extract (APE) in bisphenol-A induced reproductive toxicity in albino rats. Environ. Sci. Pollut. Res. Int., 23(12):11645-11657.

Zhao, C.; Sakaguchi, T.; Fujita, K.; Ito, H.; Nishida, N.; Nagatomo, A.; TanakaAzuma, Y. and Katakura, Y. (2016). Pomegranate-derived polyphenols reduce reactive oxygen species production via SIRT3-mediated SOD2 activation. Oxid. Med. Cell. Longev, pp:1-9.

Citation: Mohamed Atif A. Said Ahmed (2019). The protective effect of pomegranate juice on the ultrastructure of the testes in adult rat treated with Bisphenol-A. Ann. Phytomed., 8(1):101-109. 